\title{
Effects of palliative radiotherapy and bisphosphonate usage on bone turnover marker levels in cancer patients with osteolytic bone metastases
}

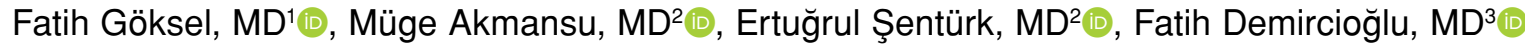 \\ ${ }^{1}$ Department of Radiation Oncology, Dr. Abdurrahman Yurtaslan Ankara Oncology Training and Research Hospital, Ankara, Turkey \\ ${ }^{2}$ Department of Radiation Oncology, Gazi University Faculty of Medicine, Ankara, Turkey \\ ${ }^{3}$ Department of Radiation Oncology, Kartal Dr. Lütfi Kırdar Training and Research Hospital, Istanbul, Turkey
}

Bone is one of the most frequent sites of metastases. Cancers of prostate, breast, lung, and kidney frequently metastasize to bones. ${ }^{[1,2]}$ In $70 \%$ of advanced prostate and breast cancers, bone metastases are observed. ${ }^{[3]}$ Advanced therapy regimens increase life expectancy in cancer patients, thereby, increasing the incidence of bone metastases. ${ }^{[4]}$ Besides being the most frequent cause of severe cancer pain, bone metastases cause also pathological fractures, life-threatening hypercalcemia, and spinal cord compression.

Bone metastases cause a dysregulation of the bone metabolism. According to the alterations of the bone structure, metastases are classified as osteolytic, osteoblastic or mixed type. Mechanisms induced particularly by osteoclasts cause both destruction due to deterioration of bone regulation and

Received: May 21, 2020

Accepted: August 27, 2020

Published online: November 19, 2021

Correspondence: Fatih Göksel, MD. Dr. Abdurrahman Yurtaslan Ankara Onkoloji Eğitim ve Araştırma Hastanesi Radyasyon

Onkolojisi Kliniği, 06200 Yenimahalle, Ankara, Türkiye.

E-mail: fatingoksel@gmail.com

\section{Doi: $10.52312 / j d r s .2021 .76037$}

Citation: Göksel F, Akmansu M, Sentürk E, Demircioğlu F. Effects of palliative radiotherapy and bisphosphonate usage on bone turnover marker levels in cancer patients with osteolytic bone metastases. Jt Dis Relat Surg 2021;32(3):705-712.

(O2021 All right reserved by the Turkish Joint Diseases Foundation

This is an open access article under the terms of the Creative Commons Attribution-NonCommercial License, which permits use, distribution and reproduction in any medium, provided the original work is properly cited and is not used for commercial purposes (http://creativecommons.org/licenses/by-nc/4.0/)

\section{ABSTRACT}

Objectives: In this study, we aimed to investigate the bone turnover marker levels according to bisphosphonate usage and radiotherapy (RT) in cancer patients with metastases in osteolytic pattern.

Patients and methods: A total of 52 patients (13 males, 39 females; median age: 52 years; range, 37 to 78 years) treated with RT for osteolytic bone metastases between April 2005 and April 2006 were retrospectively analyzed. Bone-specific alkaline phosphatase (BAP), amino-terminal cross-linked telopeptide of type I collagen (NTX-I), amino-terminal propeptide of type I procollagen (PINP), osteocalcin (OC), deoxypyridinoline (DPD), pyridinoline (PYD), alkaline phosphatase (ALP), creatinine, calcium $(\mathrm{Ca})$, phosphate $(\mathrm{P})$, magnesium $(\mathrm{Mg})$, and 24-h urine $\mathrm{Ca}$ levels were measured in blood and urine before the initiation of RT, six weeks and six months after RT.

Results: A decrease in BAP, PINP, and creatinine levels was observed after RT (Week $6 \mathrm{p}=0.006$, Month $6 \mathrm{p}=0.008$ ). Sixteen patients who already used bisphosphonate before RT were excluded from statistical calculation. The remaining 36 patients who were treated with bisphosphonate after the first blood test were evaluated separately. In this group of patients, BAP, PINP, NTX, creatinine, and Ca levels significantly increased at six weeks after RT. The PINP and creatinine values significantly decreased at six months after RT. The variation between two different RT arms was assessed with repeated measures variance analysis. There was a statistically significant difference for NTX, OC, and creatinine levels between the first and second measurements.

Conclusion: Radiotherapy is an effective method in the treatment of osteolytic bone metastases. Bone turnover markers can provide an objective evaluation on RT response and parallel to imaging modalities criteria for evaluation. Bisphosphonates may alter the levels of these indicators. However, in this study, there were no statistically significant differences between the levels of markers for two different RT schedules.

Keywords: Amino-terminal cross-linked telopeptide of type I collagen, amino-terminal propeptide of type I procollagen, bone turnover marker, osteolytic bone metastasis, palliative radiotherapy.

osteolytic metastases. ${ }^{[5]}$ Altered microenvironment of metastases is associated with the release of many molecules. ${ }^{[1]}$ 
The changes caused on bone turnover by these molecules are correlated with bone marker levels. ${ }^{[6]}$ Biochemical markers of bone turnover can be categorized in two main groups, namely bone formation and degradation markers. ${ }^{[7]}$ In osteolytic bone metastases, the increased amounts of degradation markers in the form of collagen degradation products, matrix proteins, and osteoclastic enzymes are observed. ${ }^{[8]}$

N-terminal telopeptide (NTX) and C-terminal telopeptide (CTX) resulting from degradation of cross-linked telopeptides, hydroxyproline from collagen degradation, deoxypyridinoline (DPD), and pyridinoline (PYD) are the primary markers of bone resorption. ${ }^{[6,7]}$ An enzymatic marker of bone resorption is tartrate-resistant acid phosphatase (TRACP), which is an enzyme secreted in high amounts by bone resorbing osteoclasts. ${ }^{[7]}$ On the other hand, alkaline phosphatase (ALP) and bone-specific alkaline phosphatase (BAP) are the enzymes showing osteoblastic activity and the primary markers of bone formation. ${ }^{[9]}$ Amino-terminal propeptide of type I procollagen (PINP) and carboxy-terminal propeptide of type I procollagen (PICP) are also specific products of proliferating osteoblasts and markers of bone formation. ${ }^{[9]}$

However, the clinical use of these markers is limited. Measurement of these markers may be helpful in detecting the presence of metastases. They may also have a predictive value in assessing therapeutic effectiveness of bisphosphonate usage and radiotherapy (RT), which are applied in the treatment of bone metastases. These markers are helpful in predicting skeletal-related events and the prognosis of bone metastases. In the present study, we aimed to investigate the effects of bisphosphonate usage and different RT regimens on bone turnover markers in cancer patients with metastases in osteolytic pattern.

\section{PATIENTS AND METHODS}

This single-center, retrospective study was conducted at Gazi University, Faculty of Medicine, Department of Radiation Oncology between April 2005 and April 2006. A total of 52 patients ( 13 males, 39 females; median age: 52 years; range, 37 to 78 years) treated with RT for osteolytic bone metastases were included. Osteolytic bone metastases were present in all patients, and these lesions were detected by biopsy, scintigraphy, fluorodeoxyglucose positron emission tomography, or magnetic resonance imaging. Inclusion criteria were as follows: receiving palliative RT by two different dose fractionations as $20 \mathrm{~Gy} / 5$ fraction and $30 \mathrm{~Gy} / 10$ fraction; using bisphosphonate; being older than 18 years old; and having bone turnover markers evaluated. Exclusion criteria were as follows: previous RT to the same site; a Karnofsky Performance Scale (KPS) of $<50$; major surgical operation history within the last two weeks; and medical therapy history which may affect the bone turnover marker levels. All patients' hepatic and renal function tests were evaluated and patients with chronic renal disease or any hepatic disease were also excluded. A written informed consent was obtained from each patient. The study protocol was approved by the Gazi University, Faculty of Medicine, Ethics Committee (No: 102, Date: 12.05.2005). The study was conducted in accordance with the principles of the Declaration of Helsinki.

\section{RT protocol}

External RT was applied to all the patients. Twenty-nine patients received 30 Gy in 10 fractions and 23 patients received 20 Gy in five fractions. In vertebral metastases, one vertebra above and one vertebra below was also included. Radiotherapy was applied to a parallel opposed field in cervical vertebral metastases and with a single posterior field in other vertebral regions. In all non-vertebral metastases, a $3-\mathrm{cm}$ margin was given to the lytic volume and two parallel opposed fields were used for RT.

\section{Biochemical evaluation}

During therapy, bone turnover markers were evaluated. The BAP, amino-terminal cross-linked telopeptide of type I collagen (NTX-I), PINP, osteocalcin (OC), DPD, PYD, ALP, creatinine, calcium $(\mathrm{Ca})$, phosphate $(\mathrm{P})$, magnesium $(\mathrm{Mg})$, and 24 -h urine Ca levels were measured. Of note, ALP, BAP, and PINP are the markers of bone formation, while NTX, DPD, PYD, and Ca are markers of the bone resorption. Blood and urine analyses were performed before RT and at six weeks and six months after RT. The PYD was evaluated from spot urine analysis and $\mathrm{Ca}$ from 24-h urine sample. All other markers were evaluated from blood samples. The marker level difference from all three measurements was evaluated. The marker level difference was also correlated with RT dose fractionation, bisphosphonate usage, chemotherapy usage history, and with further oncological features. As bisphosphonate, $4 \mathrm{mg} / 5 \mathrm{~mL}$ zoledronic acid (Zometa ${ }^{\circledR}$; Novartis Pharmaceuticals, Istanbul, Turkey) was diluted in $100 \mathrm{~mL}$ isotonic solution and administered as an intravenous infusion for $15 \mathrm{~min}$.

\section{Statistical analysis}

Statistical analysis was performed using the SPSS version 13.0 software (SPSS Inc., Chicago, IL, 
USA). Descriptive data were expressed in median (min-max) or number and frequency, where applicable. The non-parametric Mann-Whitney U test was used to analyze correlation between patients and treatment characteristics and bone turnover markers. The Wilcoxon signed-rank test was used to analyze correlation between repeated measurements of bone turnover markers. The correlation between two RT fractionation schemes and bone turnover markers was evaluated with repeated measurement variance analysis. A $p$ value of $<0.05$ was considered statistically significant.

\section{RESULTS}

Of the patients, 38 had breast cancer, 11 had prostate cancer, and three had lung cancer. Twenty-nine patients were irradiated with 3 Gy daily dose with 10 fractions (total dose 30 Gy) and 23 patients with 4 Gy daily dose with 5 fractions (total dose $20 \mathrm{~Gy}$ ). Patient demographics and disease characteristics are shown in Table I.

Patients' characteristics and pre-treatment marker levels were also evaluated. The BAP, ALP, NTX, PINP, OC, DPD, and PYD levels were lower in male patients compared to females. These values were significant for BAP and PINP $(\mathrm{p}<0.05)$. Urine PYD, ALP, and creatinine levels were significantly higher in patients aged $>50$ years. However, in the same age group, 24-h urine Ca values were significantly lower ( $<<0.05$ for both). Marker levels in patients receiving chemotherapy before RT were similar to those not receiving chemotherapy.

Sixteen patients were given bisphosphonate before RT. As the bone formation markers, BAP, ALP and PINP were significantly higher in the group using bisphosphonate $(\mathrm{p}=0.016, \mathrm{p}=0.001, \mathrm{p}=0.004$, respectively). Markers of bone resorption, NTX, and blood Ca levels were higher in the group using bisphosphonate, while the other resorption markers had similar results. Only PINP levels were statistically significant $(\mathrm{p}=0.042)$. The relationship between patient specifications and pre-treatment marker levels is given in Table II.

Changes in marker levels were investigated in all patients. The results between the primary measurement, second, and third measurements are given in Table III. Markers of bone formation BAP, PINP, and creatinine showed a statistically significant decrease at six weeks in all the patients $(p=0.006$, $\mathrm{p}=0.02$, and $\mathrm{p}=0.02$, respectively). The BAP and PINP measurements at six months showed a further decrease $(p=0.08$ and $p=0.002$, respectively). Also, the creatinine value at six months was lower than baseline $(p=0.036)$.
The ALP value showed a steep decline between baseline and six-month measurement; however, this decline was not statistically significant. The rest of bone turnover markers showed no significant differences.

After baseline measurements, bisphosphonate was started for 36 patients who did not use it before. As these biomarkers are affected by many factors such as chemotherapy intake, surgery, previous RT, and chronic kidney and liver diseases, these patient groups were not evaluated. In these patients, the effect of bisphosphonate on bone turnover markers was investigated. The BAP, PINP, NTX, creatinine, and $\mathrm{Ca}$ levels showed a statistically significant increase at six weeks $(\mathrm{p}=0.01, \mathrm{p}=0.03$, $\mathrm{p}=0.004, \mathrm{p}=0.02$, and $\mathrm{p}=0.01$, respectively). The PINP and creatinine showed a significant decrease at six months ( $\mathrm{p}=0.001$ and $\mathrm{p}=0.002$, respectively). The BAP

\begin{tabular}{|c|c|c|}
\hline \multicolumn{3}{|c|}{$\begin{array}{c}\text { TABLE I } \\
\text { Demographic and disease characteristics of patients }\end{array}$} \\
\hline Characteristics & $\mathrm{n}$ & $\%$ \\
\hline \multicolumn{3}{|l|}{ Age (year) } \\
\hline$\geq 50$ & 27 & 51.9 \\
\hline$<50$ & 25 & 48.1 \\
\hline \multicolumn{3}{|l|}{ Sex } \\
\hline Male & 13 & 25 \\
\hline Female & 39 & 75 \\
\hline \multicolumn{3}{|c|}{ Performance score (KPS) } \\
\hline$\geq 80$ & 45 & 86.5 \\
\hline$\leq 70$ & 7 & 13.5 \\
\hline \multicolumn{3}{|l|}{ RT scheme } \\
\hline $3 \mathrm{~Gy}^{*} 10 \mathrm{fr}$ & 29 & 55.8 \\
\hline $4 \mathrm{~Gy}{ }^{*} \mathrm{fr}$ & 23 & 44.2 \\
\hline \multicolumn{3}{|l|}{ Breast cancer } \\
\hline Yes & 38 & 73.1 \\
\hline No & 14 & 26.9 \\
\hline \multicolumn{3}{|c|}{ Visceral metastases } \\
\hline Present & 12 & 23.1 \\
\hline Absent & 40 & 76.9 \\
\hline \multicolumn{3}{|c|}{ Aromatase inhibitor usage } \\
\hline Yes & 14 & 26.9 \\
\hline No & 38 & 73.1 \\
\hline \multicolumn{3}{|c|}{ Chemotherapy history } \\
\hline Yes & 15 & 28.9 \\
\hline No & 37 & 71.1 \\
\hline \multicolumn{3}{|c|}{ Bisphosphonate usage } \\
\hline Yes & 16 & 30.8 \\
\hline No & 36 & 69.2 \\
\hline
\end{tabular}




\begin{tabular}{|c|c|c|c|c|c|c|c|c|}
\hline \multirow{3}{*}{$\begin{array}{l}\text { Markers } \\
\text { Characteristics }\end{array}$} & \multirow{2}{*}{\multicolumn{2}{|c|}{$\begin{array}{r}\text { TABL } \\
\text { pecific }\end{array}$}} & ons ar & re-treatr & t mark & evels & & \\
\hline & & & \multicolumn{2}{|c|}{ NTX } & \multicolumn{2}{|c|}{ PINP } & \multicolumn{2}{|c|}{ Osteocalcin } \\
\hline & Mean & $p$ & Mean & $p$ & Mean & $p$ & Mean & $p$ \\
\hline Age (year) & & $<0.001$ & & $<0.001$ & & $<0.001$ & & $<0.001$ \\
\hline$\geq 50$ & 29.74 & & 28.93 & & 28.9 & & 27.13 & \\
\hline$<50$ & 23 & & 23.88 & & 22.98 & & 24.82 & \\
\hline Sex & & 0.023 & & 0.051 & & 0.08 & & $<0.001$ \\
\hline Male & 18.23 & & 19.38 & & 19.88 & & 25.08 & \\
\hline Female & 29.26 & & 28.87 & & 28.09 & & 26.32 & \\
\hline Performance score (KPS) & & 0.029 & & $<0.001$ & & $<0.001$ & & $<0.001$ \\
\hline$\geq 80$ & 24.69 & & 25.31 & & 25.18 & & 25.65 & \\
\hline$\leq 70$ & 38.14 & & 34.14 & & 32.17 & & 28.21 & \\
\hline Breast cancer & & 0.076 & & $<0.001$ & & $<0.001$ & & $<0.001$ \\
\hline Yes & 28.76 & & 27.92 & & 26.97 & & 26.35 & \\
\hline No & 20.36 & & 22.64 & & 23.43 & & 25.07 & \\
\hline Visceral metastases & & $<0.001$ & & $<0.001$ & & $<0.001$ & & $<0.001$ \\
\hline Present & 30.75 & & 24.5 & & 26.42 & & 23.68 & \\
\hline Absent & 25.23 & & 27.1 & & 25.87 & & 26.64 & \\
\hline Aromatase inhibitor usage & & $<0.001$ & & $<0.001$ & & $<0.001$ & & $<0.001$ \\
\hline Yes & 27.46 & & 22.77 & & 25.08 & & 30.85 & \\
\hline No & 25.5 & & 27.11 & & 25.65 & & 23.62 & \\
\hline Chemotherapy history & & $<0.001$ & & $<0.001$ & & $<0.001$ & & $<0.001$ \\
\hline Yes & 25.71 & & 26.79 & & 28.71 & & 24.23 & \\
\hline No & 25.24 & & 25 & & 23.51 & & 25.28 & \\
\hline Bisphosphonate usage & & 0.087 & & $<0.001$ & & 0.042 & & $<0.001$ \\
\hline Yes & 26.77 & & 26.03 & & 26.61 & & 26.0 & \\
\hline No & 18.1 & & 21 & & 16.5 & & 18.8 & \\
\hline
\end{tabular}

\begin{tabular}{|c|c|c|c|c|c|c|c|c|}
\hline \multicolumn{9}{|c|}{$\begin{array}{l}\text { TABLE II } \\
\text { Continues }\end{array}$} \\
\hline Markers & \multicolumn{2}{|c|}{ DPD } & \multicolumn{2}{|c|}{ PYD (urine) } & \multicolumn{2}{|c|}{ ALP } & \multicolumn{2}{|c|}{ Creatinine } \\
\hline Characteristics & Mean & $p$ & Mean & $p$ & Mean & $p$ & Mean & $p$ \\
\hline Age (year) & & $<0.001$ & & 0.010 & & 0.040 & & 0.001 \\
\hline$\geq 50$ & 17.38 & & 10.83 & & 30.02 & & 32.26 & \\
\hline$<50$ & 20.24 & & 5.0 & & 21.48 & & 18.96 & \\
\hline Sex & & $<0.001$ & & $<0.001$ & & $<0.001$ & & 0.026 \\
\hline Male & 14.89 & & 5.0 & & 21.92 & & 33.81 & \\
\hline Female & 20.32 & & 8.5 & & 27.39 & & 23.33 & \\
\hline Performance score (KPS) & & $<0.001$ & & 0.045 & & 0.073 & & $<0.001$ \\
\hline$\geq 80$ & 18.06 & & 6.58 & & 24.51 & & 24.78 & \\
\hline$\leq 70$ & 25.0 & & 6.2 & & 35.36 & & 33.64 & \\
\hline Breast cancer & & 0.047 & & $<0.001$ & & $<0.001$ & & 0.001 \\
\hline Yes & 21.0 & & 7.18 & & 26.26 & & 21.28 & \\
\hline No & 12.78 & & 8.67 & & 25.32 & & 38.46 & \\
\hline Visceral metastases & & $<0.001$ & & $<0.001$ & & $<0.001$ & & $<0.001$ \\
\hline Present & 20.0 & & 6.5 & & 29.71 & & 21.63 & \\
\hline Absent & 18.81 & & 7.67 & & 24.86 & & 27.35 & \\
\hline Aromatase inhibitor usage & & $<0.001$ & & $<0.001$ & & $<0.001$ & & $<0.001$ \\
\hline Yes & 21.89 & & 6.2 & & 22.38 & & 20.54 & \\
\hline No & 18.07 & & 8.22 & & 26.59 & & 27.24 & \\
\hline Chemotherapy history & & $<0.001$ & & $<0.001$ & & $<0.001$ & & $<0.001$ \\
\hline Yes & 20.56 & & 5.67 & & 27.79 & & 22.71 & \\
\hline No & 17.81 & & 8.0 & & 23.89 & & 25.91 & \\
\hline Bisphosphonate usage & & $<0.001$ & & $<0.001$ & & 0.065 & & $<0.001$ \\
\hline Yes & 17.96 & & 7.42 & & 26.41 & & 24.34 & \\
\hline No & 18.14 & & 8.0 & & 17.25 & & 25.1 & \\
\hline
\end{tabular}




\begin{tabular}{|c|c|c|c|c|c|c|c|c|}
\hline \multicolumn{9}{|c|}{$\begin{array}{l}\text { TABLE II } \\
\text { Continues }\end{array}$} \\
\hline \multirow{2}{*}{$\begin{array}{l}\text { Markers } \\
\text { Characteristics }\end{array}$} & \multicolumn{2}{|c|}{$\mathrm{Ca}$ (blood) } & \multicolumn{2}{|c|}{ P (Phosphate) } & \multicolumn{2}{|c|}{$\mathrm{Mg}$} & \multicolumn{2}{|c|}{ Ca (24-h urine) } \\
\hline & Mean & $p$ & Mean & $p$ & Mean & $p$ & Mean & $p$ \\
\hline Age (year) & & $<0.001$ & & $<0.001$ & & $<0.001$ & & 0.020 \\
\hline$\geq 50$ & 27.13 & & 27.87 & & 20.33 & & 19.91 & \\
\hline$<50$ & 24.73 & & 23.9 & & 24.56 & & 28.66 & \\
\hline Sex & & $<0.001$ & & $<0.001$ & & 0.013 & & $<0.001$ \\
\hline Male & 25.12 & & 25.15 & & 29.63 & & 25.83 & \\
\hline Female & 26.3 & & 26.29 & & 19.05 & & 23.37 & \\
\hline Performance score (KPS) & & $<0.001$ & & $<0.001$ & & $<0.001$ & & $<0.001$ \\
\hline$\geq 80$ & 25.98 & & 25.06 & & 22.16 & & 24.36 & \\
\hline$\leq 70$ & 26.14 & & 31.93 & & 21.0 & & 21.0 & \\
\hline Breast cancer & & $<0.001$ & & $<0.001$ & & $<0.001$ & & $<0.001$ \\
\hline Yes & 26.78 & & 26.15 & & 20.55 & & 25.25 & \\
\hline No & 23.93 & & 25.61 & & 25.35 & & 20.73 & \\
\hline Visceral metastases & & $<0.001$ & & $<0.001$ & & 0.086 & & $<0.001$ \\
\hline Present & 26.42 & & 26.96 & & 28.88 & & 27.75 & \\
\hline Absent & 20.43 & & 25.71 & & 20.43 & & 22.99 & \\
\hline Aromatase inhibitor usage & & $<0.001$ & & $<0.001$ & & $<0.001$ & & 0.083 \\
\hline Yes & 30.5 & & 27.08 & & 22.46 & & 29.92 & \\
\hline No & 23.74 & & 24.95 & & 21.82 & & 21.97 & \\
\hline Chemotherapy history & & $<0.001$ & & $<0.001$ & & $<0.001$ & & $<0.001$ \\
\hline Yes & 22.25 & & 22.57 & & 22.64 & & 23.68 & \\
\hline No & 26.1 & & 25.97 & & 21.1 & & 23.44 & \\
\hline Bisphosphonate usage & & 0.077 & & $<0.001$ & & $<0.001$ & & $<0.001$ \\
\hline Yes & 26.34 & & 23.91 & & 20.74 & & 21.7 & \\
\hline No & 17.5 & & 26.75 & & 21.8 & & 27.55 & \\
\hline
\end{tabular}

showed a decrease at six months, but this was not statistically significant $(p=0.089)$. Metabolic marker levels in bisphosphonate usage starting with RT are shown in Table IV.
The marker levels of the patients receiving two different fractionation RTs were analyzed using the repeated measurement variance analysis. We observed differences in the BAP, DPD, urine PYD,

\begin{tabular}{|c|c|c|c|c|c|}
\hline \multicolumn{6}{|c|}{$\begin{array}{c}\text { TABLE III } \\
\text { Marker levels of all patients }\end{array}$} \\
\hline Marker & $1^{\text {st }}$ Level & $2^{\text {nd }}$ Level & $3^{\text {rd }}$ Level & $\begin{array}{l}1 \text { vs. } 2 \\
p \text { value }\end{array}$ & $\begin{array}{l}1 \text { vs. } 3 \\
p \text { value }\end{array}$ \\
\hline BAP & 28.4 & 22.19 & 17.69 & 0.006 & 0.079 \\
\hline NTX & 25.27 & 23.05 & 24.14 & $<0.001$ & 0.088 \\
\hline PINP & 102.21 & 81.71 & 52.05 & 0.020 & 0.002 \\
\hline Osteocalcin & 11.56 & 12.01 & 12.81 & $<0.001$ & $<0.001$ \\
\hline DPD & 12.31 & 14.08 & 12.73 & $<0.001$ & $<0.001$ \\
\hline PYD & 82.34 & 84.93 & 65.57 & $<0.001$ & $<0.001$ \\
\hline ALP & 132.5 & 130.32 & 106.21 & $<0.001$ & $<0.001$ \\
\hline Creatinine & 0.9 & 0.84 & 0.85 & 0.021 & 0.036 \\
\hline Ca (blood) & 9.12 & 8.9 & 9.2 & $<0.001$ & $<0.001$ \\
\hline$P$ & 3.21 & 3.01 & 3.18 & $<0.001$ & $<0.001$ \\
\hline $\mathrm{Mg}$ & 6.73 & 13.32 & 8.7 & $<0.001$ & $<0.001$ \\
\hline Ca (24-h urine) & 104.05 & 91.73 & 99.38 & $<0.001$ & $<0.001$ \\
\hline
\end{tabular}




\begin{tabular}{|c|c|c|c|c|c|}
\hline \multicolumn{6}{|c|}{$\begin{array}{l}\text { TABLE IV } \\
\text { isphosphonate usage starting with RT }\end{array}$} \\
\hline Marker & $1^{\text {st }}$ Level & $2^{\text {nd }}$ Level & $3^{\text {rd }}$ Level & $\begin{array}{l}1 \text { vs. } 2 \\
p \text { value }\end{array}$ & $\begin{array}{l}1 \text { vs. } 3 \\
p \text { value }\end{array}$ \\
\hline BAP & 22.5 & 27.65 & 18.59 & 0.016 & 0.089 \\
\hline NTX & 22.84 & 26.05 & 24.57 & 0.036 & $<0.001$ \\
\hline PINP & 66.77 & 104.46 & 54.46 & 0.004 & 0.001 \\
\hline Osteocalcin & 12.44 & 13.17 & 13.77 & $<0.001$ & $<0.001$ \\
\hline DPD & 13.69 & 12.57 & 13.08 & $<0.001$ & $<0.001$ \\
\hline PYD & 83.46 & 80.4 & 68.27 & $<0.001$ & $<0.001$ \\
\hline ALP & 123.28 & 130.76 & 111.6 & $<0.001$ & $<0.001$ \\
\hline Creatinine & 0.84 & 0.9 & 0.84 & 0.022 & 0.021 \\
\hline Ca (blood) & 8.84 & 9.21 & 9.18 & 0.017 & $<0.001$ \\
\hline$P$ & 2.98 & 3.19 & 3.18 & $<0.001$ & $<0.001$ \\
\hline $\mathrm{Mg}$ & 15.91 & 6.59 & 6.19 & $<0.001$ & $<0.001$ \\
\hline Ca (24-h urine) & 89.77 & 92.32 & 86.31 & $<0.001$ & $<0.001$ \\
\hline
\end{tabular}

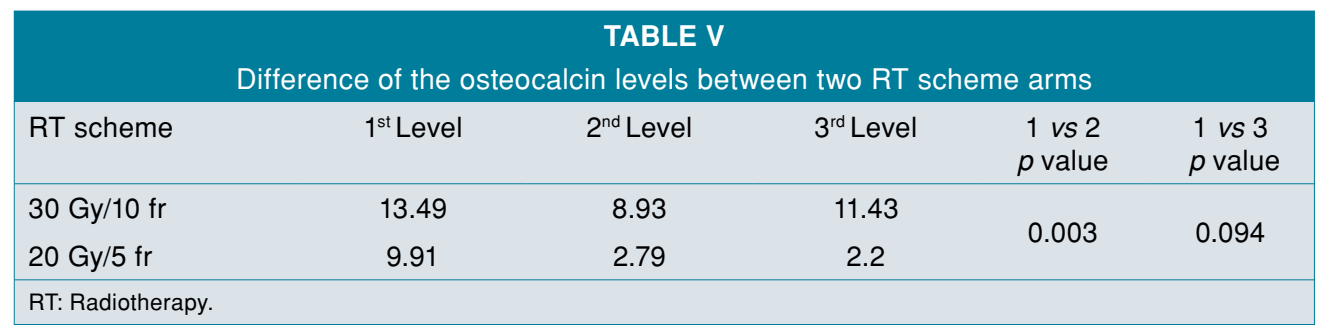

ALP, Ca, P, and $\mathrm{Mg}$ between the two treatment doses.

Among two different RT arms, primary NTX and 24-h urine $\mathrm{Ca}$ values showed a significant difference ( $p=0.001$ and $p=0.033$, respectively). The patients in 20 Gy/5 fraction arms had a median NTX value of $34.39 \mathrm{nmBCE} / \mathrm{Nmol}$, and patients in $30 \mathrm{~Gy} / 5$ fraction arms had a median value of $20.24 \mathrm{nmBCE} / \mathrm{Nmol}$. The median 24-h urine Ca levels for each arm were 19.05 and $27.67 \mathrm{mg} / \mathrm{dL}$, while they were 30.13 and $22.61 \mathrm{mg} / \mathrm{dL}$ for creatinine $(\mathrm{p}=0.067)$, respectively. Between both RT arms, only OC and creatinine showed a significant difference between the values of the initial measurement and the sixth week $(p=0.003$ and $\mathrm{p}=0.014$, respectively). All values for OC in both RT arms are shown in Table V.

\section{DISCUSSION}

The primary objective of this study was the evaluation of two palliative RT fractionation schemes on bone turnover marker rates. The secondary objective was the evaluation of bisphosphonate on bone turnover marker rates. Our study results showed that RT and bisphosphonate usage affected the biochemical markers of bone metabolism, although there were no statistically significant differences between two different dose schemes.

While RT suppressed tumor proliferation and caused pain palliation in metastatic sites, it also caused changes in bone metabolism. In the early phases of RT, soft collagen fibrils formed a coil and calcified with time. Six months after RT, the bone was remodeled into its normal structure. There are only a few studies on the effect of RT on bone turnover markers in the literature. The increased bone formation and resorption, particularly in the early periods, significantly affect marker levels. The relationship between marker levels and radiological or symptomatic response to RT is also unknown. In our study, we showed that there was a significant decline in the NTX and PINP soon after RT. In the early period, OC levels showed a slight increase, which was not statistically significant. The discrepancy among the results may be due to the complex metabolic changes 
caused by RT. The usage of bisphosphonate before RT and bisphosphonate usage starting with RT renders it difficult to evaluate the effect of RT on bone turnover markers. On the site, the usage of bisphosphonate in all patients provided us the opportunity to evaluate two different fractionation schemes, but the sample size in the subgroups was small. In the literature, there is no study investigating the effect of different RT fractionations on bone metabolism markers. In our study, we observed no significant differences between RT dose schemes by comparing pre-RT, Week 6, and Month 6 bone turnover markers.

Evaluating 36 patients who started bisphosphonate at the same time with RT, we observed an increase in markers of bone formation and degradation. In particular, in these patients, we observed a statistically significant increase in the bone formation marker of PINP, which increased more than two-fold according to baseline. The BAP, ALP, and OC showed also an increase, although not as much as PINP. Over time after the treatment, the increase of bone formation markers tended to stop. Levels at six months were similar to baseline values. This finding indicates that bone formation is completed within six months after therapy. In addition, bone resorption markers such as NTX and urine Ca showed a statistically significant increase in the early phases of therapy. These changes in the early stage of the treatment may be an indicator that bone metabolism is induced, bone resorption decreases, and bone formation increases. Later, an increase in the marker levels stopped, although bisphosphonate therapy continued. This can be attributed to the effect of RT on the bones.

In a recent study, administering zoledronic acid to prostate cancer patients caused a significant decrease of degradation markers such as NTX within first $24 \mathrm{~h}$, but this decrease could not be verified after one month. ${ }^{[10]} \mathrm{A}$ significant increase in BAP levels was also observed in the early stages. The use of pamidronate in another study showed that the decrease of bone resorption marker levels including NTX ceased at four weeks and started to increase thereafter. ${ }^{[1]}$ Even an administration of a second dose could not cause any decrease. In a study including breast cancer patients, a loading dose of ibandronate caused a significant reduction in bone formation and resorption markers. ${ }^{[12]}$ In our study, bisphosphonate was used in 16 patients before RT and their baseline blood values of ALP, BAP, and PINP were statistically significantly higher, proving its anti-resorptive properties.

Bone is a major metastasis site for various solid tumors such as breast, prostate, and lung cancer. Tumor colonization in the metastatic area causes changes in the bone metabolism. Metastases may have osteolytic or osteoblastic metabolisms. Changes in the metabolism cause the release of some enzymes and biochemical compounds due to increased resorption and formation. These markers are named as bone metabolism markers. The use of bone metabolism markers in the detection of metastases, forecasting prognosis, and response to treatment are still matters of investigation. In our study, we only included patients with osteolytic metastases.

Correlation of marker levels with the presence of metastasis, size, and pain severity is a known fact. ${ }^{[13,14]}$ As all our patients had bone metastases, we were not able to evaluate the effectiveness of the markers on determining metastases. According to the literature, PYD, DPD, and NTX levels increase in patients with bone metastases. ${ }^{[15-18]}$ Some other studies, however, have claimed that although no metastatic cancer is present, cancer patients may show high marker rates. ${ }^{[19]}$ The relationship between bone marker levels and progression of bone metastases, predicting therapy response and survival rates were also investigated. Coleman et al. ${ }^{[20]}$ investigated skeletal-related cases in 1,824 patients using bisphosphonate. The patient group with initially medium-to-high NTX levels was compared with patients with low NTX levels at the beginning and showed a two-fold increase in complications. In the aforementioned study, progression of bone lesions and death risk was higher in high-NTX group. Brown et al. ${ }^{[21]}$ evaluated a Phase III study retrospectively and found both that patients with higher baseline NTX values had an increased risk of skeletal-related events and that the median time for the first skeletal complications was statistically significantly shorter. In the same study, higher incidences of bone disease progression and death rates in patients with bone metastases were related to high NTX values. Also, higher BAP values were shown to be related to negative clinical outcomes. ${ }^{[20,21]}$

In another prospective study using Rhenium-186 hydroxyethylidene diphosphonate (186Re-HEDP), the effect of palliative treatment on bone marker levels and predictive value of marker levels on clinical outcomes were investigated in patients with prostate cancer. ${ }^{[23]}$ In $77.8 \%$ of the patients, there was pain reduction with therapy. None of the markers could predict therapeutic response on its own. Baseline NTX/PINP, PICP/PINP, and NTX/CTX ratios and a decrease of NTX and PICP values after treatment were related to pain response. The NTX decreasing more than $20 \%$ and a baseline NTX/PINP ratio of $\geq 1.2$ correlated with a better and longer therapy response and, therefore, they were considered marker-related 
predictors. In our study, serum NTX, BAP, ALP, PINP, and Ca values were significantly affected by the treatments applied. Accordingly, we believe that these biomarkers can be used in patients with bone metastases to determine the treatment response and disease progression.

Rief et al. ${ }^{[22]}$ evaluated biochemical marker levels in patients with spinal metastases receiving RT and performing isometric resistance training. According to their study, marker values decreased with treatment. The PINP levels had a significant correlation with local response and prevention of skeletal related events. In our study, patient population was small and follow-up period was not long enough to evaluate the predictive value of clinical outcomes.

Furthermore, our study showed that palliative RT in patients with bone metastases affected bone marker levels. Evaluation of bone turnover markers may be an objective criterion for arranging therapy options and predicting therapy outcomes. Synchronous use of bisphosphonate may cause further complex effects in bone metabolism and this may reflect differently on marker levels.

In conclusion, bone turnover markers may be important objective criteria for predicting therapy outcomes and prognosis in osteolytic bone diseases. The absence of a significant difference with different fractions shows that these markers can be used safely in all patients receiving palliative RT. However, in our study, these biomarkers were shown to be affected by both RT and bisphosphonate usage; however, when we compared the levels of markers for two different RT schedules, no statistically significant differences were observed. Based on these findings, further prospective studies are needed to investigate which biomarkers are more effective in palliative RT or bisphosphonate treatment or whether they differ according to cancer types.

\section{Declaration of conflicting interests}

The authors declared no conflicts of interest with respect to the authorship and/or publication of this article.

\section{Funding}

The authors received no financial support for the research and/or authorship of this article.

\section{REFERENCES}

1. Coleman RE. Metastatic bone disease: Clinical features, pathophysiology and treatment strategies. Cancer Treat Rev 2001;27:165-76.

2. Cecchini MG, Wetterwald A, van der Pluijm G, Thalmann GN. Molecular and biological mechanisms of bone metastasis. EAU Update Series 2005;3:214-26.

3. Coleman RE, Rubens RD. The clinical course of bone metastases from breast cancer. Br J Cancer 1987;55:61-6.
4. Al Husaini H, Wheatley-Price P, Clemons M, Shepherd FA. Prevention and management of bone metastases in lung cancer: A review. J Thorac Oncol 2009;4:251-9.

5. Roodman GD. Mechanisms of bone metastasis. N Engl J Med 2004;350:1655-64.

6. Atik OŞ, Sezgin EA, Tepedelenlioğlu HE. The role of biomarkers in osteoarthritis and osteoporosis for early diagnosis and monitoring prognosis. Eklem Hastalik Cerrahisi 2019;30:175-6.

7. Seibel MJ. Clinical use of markers of bone turnover in metastatic bone disease. Nat Clin Pract Oncol 2005;2:504-17.

8. Ferreira A, Alho I, Casimiro S, Costa L. Bone remodeling markers and bone metastases: From cancer research to clinical implications. Bonekey Rep 2015;4:668.

9. Swaminathan R. Biochemical markers of bone turnover. Clin Chim Acta 2001;313:95-105.

10. Chen T, Berenson J, Vescio R, Swift R, Gilchick A, Goodin S, et al. Pharmacokinetics and pharmacodynamics of zoledronic acid in cancer patients with bone metastases. J Clin Pharmacol 2002;42:1228-36.

11. Vinholes JJ, Purohit OP, Abbey ME, Eastell R, Coleman RE. Relationships between biochemical and symptomatic response in a double-blind randomised trial of pamidronate for metastatic bone disease. Ann Oncol 1997;8:1243-50.

12. Wang $R$, Zhang S, Jiang Z, Tian J, Wang $T$, Song S. Bone metabolism markers: Indicators of loading dose intravenous ibandronate treatment for bone metastases from breast cancer. Clin Exp Pharmacol Physiol 2017;44:88-93.

13. Lipton A, Demers L, Curley E, Chinchilli V, Gaydos L, Hortobagyi G, et al. Markers of bone resorption in patients treated with pamidronate. Eur J Cancer 1998;34:2021-6.

14. Berruti A, Dogliotti L, Gorzegno G, Torta M, Tampellini M, Tucci M, et al. Differential patterns of bone turnover in relation to bone pain and disease extent in bone in cancer patients with skeletal metastases. Clin Chem 1999;45:1240-7.

15. Body JJ, Dumon JC, Gineyts E, Delmas PD. Comparative evaluation of markers of bone resorption in patients with breast cancer-induced osteolysis before and after bisphosphonate therapy. Br J Cancer 1997;75:408-12.

16. Wada N, Fujisaki M, Ishii S, Ikeda T, Kitajima M. Evaluation of bone metabolic markers in breast cancer with bone metastasis. Breast Cancer 2001;8:131-7.

17. Ulrich U, Rhiem K, Schmolling J, Flaskamp C, Paffenholz I, Sälzer H, et al. Cross-linked type I collagen C- and $\mathrm{N}$-telopeptides in women with bone metastases from breast cancer. Arch Gynecol Obstet 2001;264:186-90.

18. Demers LM, Costa L, Lipton A. Biochemical markers and skeletal metastases. Cancer 2000;88(12 Suppl):2919-26.

19. Demers LM, Costa L, Chinchilli VM, Gaydos L, Curley E, Lipton A. Biochemical markers of bone turnover in patients with metastatic bone disease. Clin Chem 1995;41:1489-94.

20. Coleman RE, Major P, Lipton A, Brown JE, Lee KA, Smith $\mathrm{M}$, et al. Predictive value of bone resorption and formation markers in cancer patients with bone metastases receiving the bisphosphonate zoledronic acid. J Clin Oncol 2005;23:4925-35.

21. Brown JE, Cook RJ, Major P, Lipton A, Saad F, Smith M, et al. Bone turnover markers as predictors of skeletal complications in prostate cancer, lung cancer, and other solid tumors. J Natl Cancer Inst 2005;97:59-69.

22. Rief H, Omlor G, Akbar M, Welzel T, Bruckner T, Rieken S, et al. Feasibility of isometric spinal muscle training in patients with bone metastases under radiation therapy - first results of a randomized pilot trial. BMC Cancer 2014;14:67.

23. Zafeirakis A, Papatheodorou G, Arhontakis A, Gouliamos A, Vlahos L, Limouris GS. Predictive implications of bone turnover markers after palliative treatment with (186)Re-HEDP in hormone-refractory prostate cancer patients with painful osseous metastases. Eur J Nucl Med Mol Imaging 2010;37:103-13. 